\title{
Nitrogen Oxides Emissions Reduction Methods for Boilers with Air-Cooled Cyclone-Vortex Pre-Furnaces
}

\author{
Andrei V. Lesnykh*, \\ Konstantin A. Shtym and Mikhail V. Upskiy \\ Far Eastern Federal University \\ Vladivostok, Russian Federation
}

Received 06.01.2020, received in revised form 15.01.2020, accepted 20.01.2020

Abstract. This article is devoted to the features of the formation of nitrogen oxides in boilers with cyclone-vortex pre-furnaces and the possibility of using technological measures to reduce them. According to existing notion, combustion devices with high thermal voltages are characterized by high emission of nitrogen oxides. The influence of the design of the gas inlets into the combustion chamber of the cyclone-vortex pre-furnace on the emission of nitrogen oxides was defined by experimental methods.

Additionally, a study was conducted under various modes of operation of the boiler of the furnace process inside the combustion chamber of a cyclone-vortex pre-furnace. It is necessary to point that the optimal nozzle design and water-fuel ratio were selected by means of water injection.

Based on these studies, the factors affecting the formation of nitrogen oxides are identified. As a result, the most effective technological methods for low-emission operation of a 116-megawatt boiler with cyclone pre-furnaces were determined.

Keywords: cyclone vortex pre-furnaces, furnace process, nitrogen oxides, boiler plants, mechanical nozzles, harmful emission reduction, controlled incomplete combustion, water injection.

Citation: Lesnykh A.V., Shtym K.A., Upskiy M.V. Nitrogen oxides emissions reduction methods for boilers with air-cooled cyclone-vortex pre-furnaces, J. Sib. Fed. Univ. Eng. \& Technol., 2020, 13(1), 69-83. DOI: 10.17516/1999-494X-0206

(C) Siberian Federal University. All rights reserved

This work is licensed under a Creative Commons Attribution-NonCommercial 4.0 International License (CC BY-NC 4.0).

* Corresponding author E-mail address: lesnykhav@mail.ru 


\title{
Методы снижения выбросов оксидов азота
}

\author{
в котлах с воздухоохлаждаемыми \\ циклонно-вихревыми предтопками
}

\author{
А.В. Лесных, К.А. Штым, М.В. Упский \\ Дальневосточный федеральньий университет \\ Российская Федерация, Владивосток
}

\begin{abstract}
Аннотация. В данной статье рассматриваются особенности образования оксидов азота в котлах с циклонно-вихревыми предтопками и возможность применения технологических мероприятий для их снижения. По существующим представлениям топочные устройства с высокими тепловыми напряжениями характеризуются высокой эмиссией оксидов азота. Экспериментальными методами было определено влияние конструкции газовых вводов в камеру сгорания циклонно-вихревого предтопка на величину выброса оксидов азота. Проведено исследование топочного процесса внутри камеры сгорания циклонно-вихревого предтопка при различных режимах работы котла. При осуществлении впрыска воды была выбрана оптимальная конструкция форсунки и водотопливного соотношения. В результате определены факторы, влияющие на образование оксидов азота, а также наиболее эффективные технологические методы для низкоэмиссионной эксплуатации котла КВГМ-100 с циклонновихревыми предтопками.
\end{abstract}

Ключевые слова: циклонно-вихревые предтопки, топочный процесс, оксиды азота, котельные установки, механические форсунки, снижение вредных выбросов, контролируемый химический недожог, впрыск воды.

Цитирование: Лесных, А.В. Методы снижения выбросов оксидов азота в котлах с воздухоохлаждаемыми циклонновихревыми предтопками / А.В. Лесных, К.А. Штым, М.В. Упский // Журн. Сиб. федер. ун-та. Техника и технологии, 2020. 13(1). C. 69-83. DOI: 10.17516/1999-494X-0206

C 30-х гг. прошлого века в Советском Союзе и за рубежом началось активное освоение циклонно-вихревой технологии сжигания топлив. Первоначально предполагалось применение данной технологии для сжигания твердого топлива. Широкому распространению ее, скорее всего, помешали сложность аэродинамики циклонного процесса и уклон в сторону исследования камер с водоохлаждаемой конструкцией. Кафедрой теплоэнергетики ДВФУ в начале 1970-х гг. была предложена воздухоохлаждаемая конструкция камер сгорания с облегченной обмуровкой и комбинированной генерацией вихря за счет аксиального и тангенциального подвода воздуха. Первые циклонно-вихревые предтопки были установлены на котлах Шухова-Берлина, и их эксплуатация продлилась 25 лет [1]. С 1986 г., благодаря одобренной ЦКТИ, ЭНИН ВНИПИ Энергопрома и других организаций работе по модернизации паровых и водогрейных котлов с переводом на циклонно-вихревое сжигание началось активное внедрение данной технологии в большую и малую энергетику. На Дальнем Востоке около 60 котлов оснащены мазутными и газомазутными циклонно-вихревыми предтопками (далее ЦВП), единичной мощностью от 17 до 65 МВт. Прежде всего активное внедрение циклонно-вихревой технологии сжигания вызвано возможностью увеличения производительности котлов при сохранении допустимых удельных тепловых напряжений топки. Также одновременно с повышением мощности котлов удается повысить экономичность их работы за счет возможности работы при экстремально низких из- 
бытках воздуха, без применения третичного дутья и иных методов. Одними из первых паровых котлов были модернизированы котлы «Бабкок-Вилькокс» Владивостокской ТЭЦ-1, на фронтовые стены каждого из них было установлено по одному ЦВП. С их установкой удалось увеличить паропроизводительность на 15 \% (с 30 до 35 т/ч), КПД котлов при этом повысился с 80 до 90 \% при работе на мазуте.

Первыми водогрейными котлами, переведенными на циклонно-вихревое сжигание мазута, стали три котла ЭЧМ-25/35 теплопроизводительностью 30 Гкал/ч. Были модернизированы топочные камеры с установкой ширмовых поверхностей, при этом удалось достичь нагрузки в 50 Гкал/ч. КПД котлов в среднем также составляет 90 \% [1].

В дальнейшем были модернизированы и другие виды промышленных и энергетических котлов. Коллективом кафедры ТЭиТТ при обобщенном анализе данных в работе [1] отмечается снижение валовых выбросов вредных веществ, неклассические зависимости удельных выбросов оксидов азота $N O_{x}$ от компоновки предтопков на стенах топки, нагрузки и коэффициента избытка воздуха.

В 1993 г. был принят ГОСТ «Котельные установки», где введены экологические требования к котлам. Примерно в это же время появились первые электронные газовые анализаторы, которые позволили проводить экспресс-анализ удельных выбросов вредных веществ от котла. Резко встал вопрос об очистке и утилизации вод, загрязненных нефтепродуктами. В 1997 г. одновременно с модернизацией котла КВГМ-20 на циклонно-вихревое сжигание разработан и внедрен пилотный проект циклонного термообезвреживания (ЦТО) сточных вод. Очистка подтоварных вод со средней концентрацией нефтепродуктов 820 мг/л производилась выжиганием их в камере сгорания ЦВП вместе с мазутом. Принципиальная схема ЦТО представлена на рис. 1.

Для более удобной эксплуатации данной технологии была разработана специальная конструкция центробежной форсунки с раздельной подачей мазута и загрязненной воды. По центральному каналу форсунки подавалась замазученная вода, а по внешнему - мазут.

Первые испытания данной системы были проведены на котле КВГМ-20. Зависимость относительной концентрации загрязняющих веществ от доли впрыска воды представлена на рис. 2. Следует отметить, что высокие тепловые напряжения камеры сгорания ЦВП позволяют увеличить долю впрыска воды до 45 \% без срыва факела. Испытания проводили на нагрузке 8,5 Гкал/ч. Начальная концентрация оксидов азота $N O_{x}$ составляла $237 \mathrm{~m} / \mathrm{m}^{3}$. С увеличением доли впрыска наблюдается плавное снижение концентрации оксидов азота в дымовых газах, приблизительно 5 мг на 10 \% впрыскиваемой воды. Наименьшая концентрация существует при доле впрыска $42 \%$ и составляет 217 мг/м³. Повышение доли впрыска свыше 25 \% приводит к повышению концентрации СО, за счет значительного снижения температур в топочной камере.

Подобные системы ЦТО были применены также на котлах КВГМ-100-150МЦ и БК3-75$16 М Ц$ где были получены хорошие результаты по снижению выбросов оксидов азота.

С началом газификации Дальнего Востока на применение циклонно-вихревой технологии были переведены и некоторые котлы тепловых электрических станций. Наибольшее число вариантов ввода газа в камеру сгорания ЦВП было опробовано на котле БКЗ-120-100ГМ Охинской ТЭЦ [1]. 


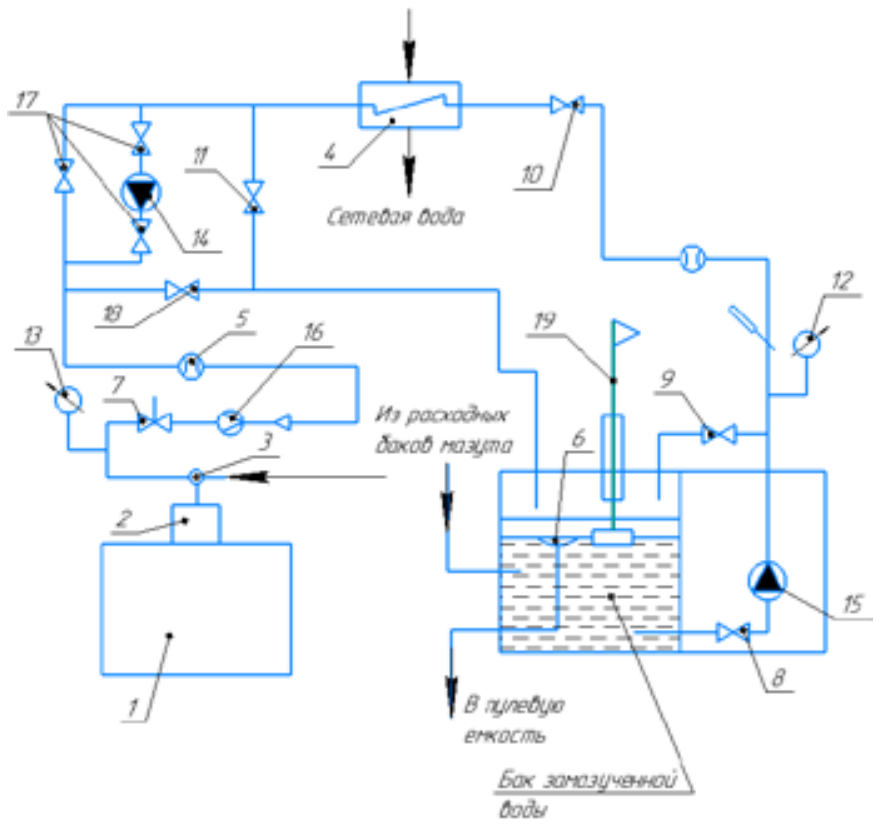

Рис. 1. Принципиальная схема ЦТО (циклонного термообезвреживания): 1 - котел; 2 - ЦВП; 3 Многосопловая двухканальная центробежная форсунка; 4 - вододяной теплообменник; 5 - фильтр грубой очистки; 6 - переливная труба; 7 - регулирующая арматура; 8, 9, 10, 11, 17, 18 - кран шаровой; 12, 13 - манометры; 14 - основной насос; 15 - насос первого подъема; 16 - расходомер; 19 - поплавковый указатель уровня

Fig. 1. Schematic diagram of CHT (cyclone heat treatment): 1 - boiler; 2 - CVP; 3 - multi-nozzle two-channel centrifugal nozzle; 4 - water heat exchanger; 5 - coarse filter; 6 - overflow pipe; 7 - control valves; $8,9,10,11$, 17,18 - ball valve; 12,13 - manometers; 14 - the main pump; 15 - the pump of the first rise; 16 - flow meter; 19 - Float level indicator

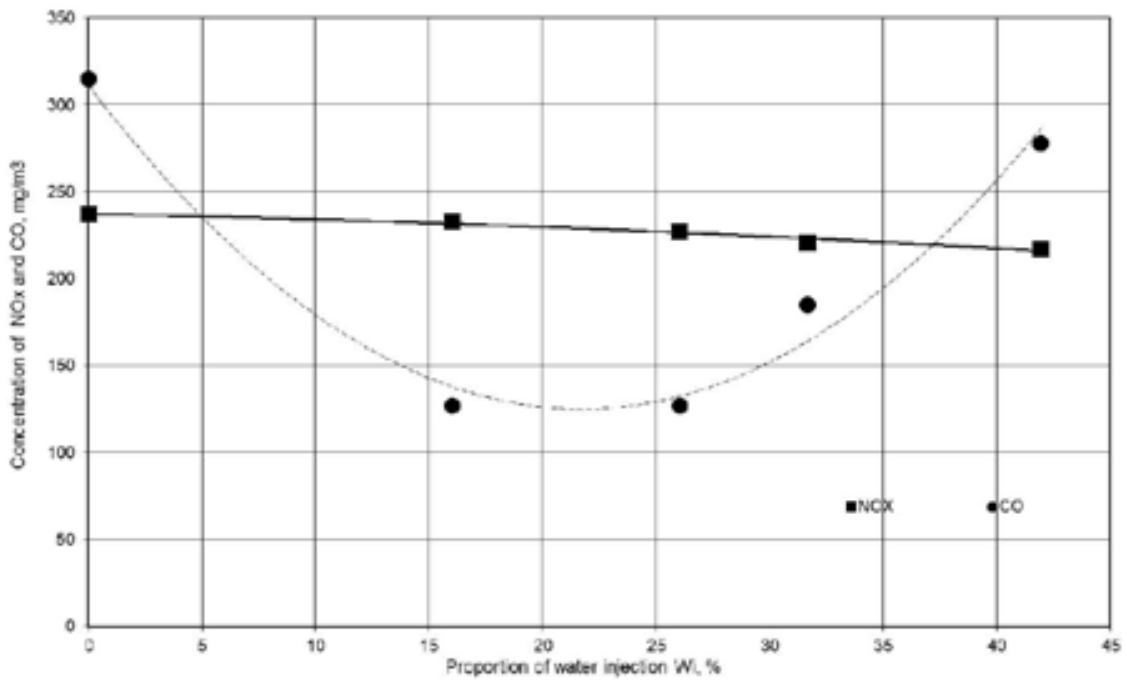

Рис. 2. Зависимость концентрации вредных выбросов от доли впрыска воды

Fig. 2. Dependence of harmful emissions concentration on the proportion of water injection 
Для оценки технико-экономических показателей работы котла до реконструкции были проведены балансовые опыты на нагрузках 65, 80, 95, 113 т/ч. При работе котла с оптимальными избытками воздуха потери тепла с химическим недожогом $\left(\mathrm{q}_{3}\right)$ во всем диапазоне нагрузок отсутствуют. Потери тепла с уходящими газами в исследуемом диапазоне нагрузок составляют $\mathrm{q}_{2}=7,35-6,89 \%$ ( $\mathrm{q}_{\text {расч. }}=2-4,8 \%$ ). Большие потери тепла с уходящими газами в исследуемом диапазоне нагрузок объясняются повышенными присосами воздуха в топку и конвективную шахту $\left(\Delta \alpha_{\mathrm{r}}^{\prime \prime}=13 \%, \Delta \alpha_{\text {кш }}=20 \%\right.$, в то время как паспортные значения составляют $\Delta \alpha_{\mathrm{r}}^{\prime \prime}=5 \%$, $\Delta \alpha_{\text {кш }}=10 \%$ ), что в итоге приводит к чрезмерно высоким избыткам воздуха в уходящих газах. КПД котла “брутто” в указанном диапазоне нагрузок изменяется от 91,54 до 92,35 \% и имеет явно выраженный максимум в диапазоне 85-115 т/ч. С ростом нагрузки до 113 т/ч потери на тягу и дутье уменьшились до 1,1 \%. КПД котла “нетто” подсчитывался без учета расхода электроэнергии на питательные насосы и в исследуемом диапазоне изменяется от 90,25 до 91,22 \%. Удельные расходы электроэнергии на тягу и дутье в исследуемом диапазоне нагрузок находится на уровне 3,76-3,08 кВт*ч/т пара. Первичной целью модернизации котла являлось повышение его производительности, а также надежность работы на резервном жидком топливе. В объеме проекта разработаны технические решения, внедрение которых позволило бы достичь нагрузки 140-150 т/ч, а также выполнен расчет элементов котла для повышенной производительности. Техническое решение включает в себя замену имеющихся на котле восьми вихревых горелок на два циклонных предтопка, замена только третьей ступени трубчатого воздухоподогревателя на дополнительную ступень экономайзера по условиям тепловой схемы ТЭЦ. Общие виды модернизированного котла приведены на рис. 3. При модернизации котла рассматривали два варианта конструкции предтопков (рис. 4).
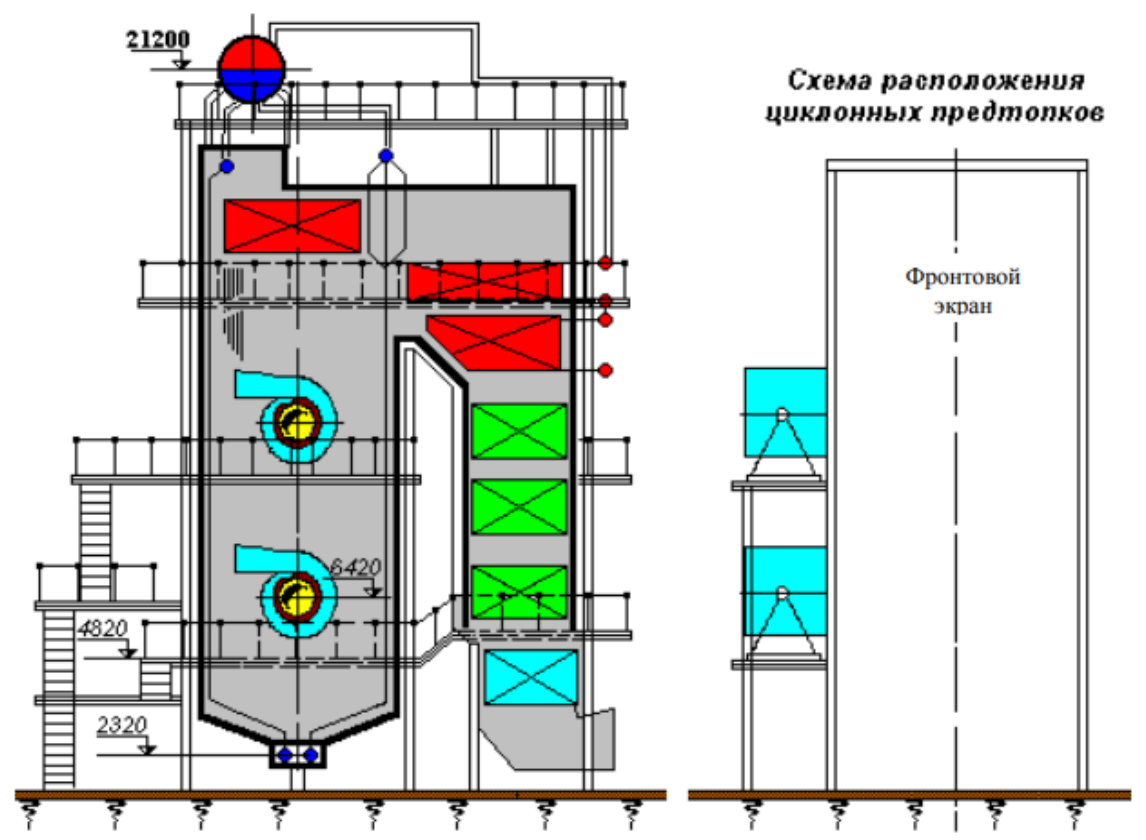

Рис. 3. Модернизированный котел БКЗ-120-100МЦ Охинской ТЭЦ

Fig. 3. Upgraded boiler BKZ-120-100MC of the Okhinskaya CHPP 


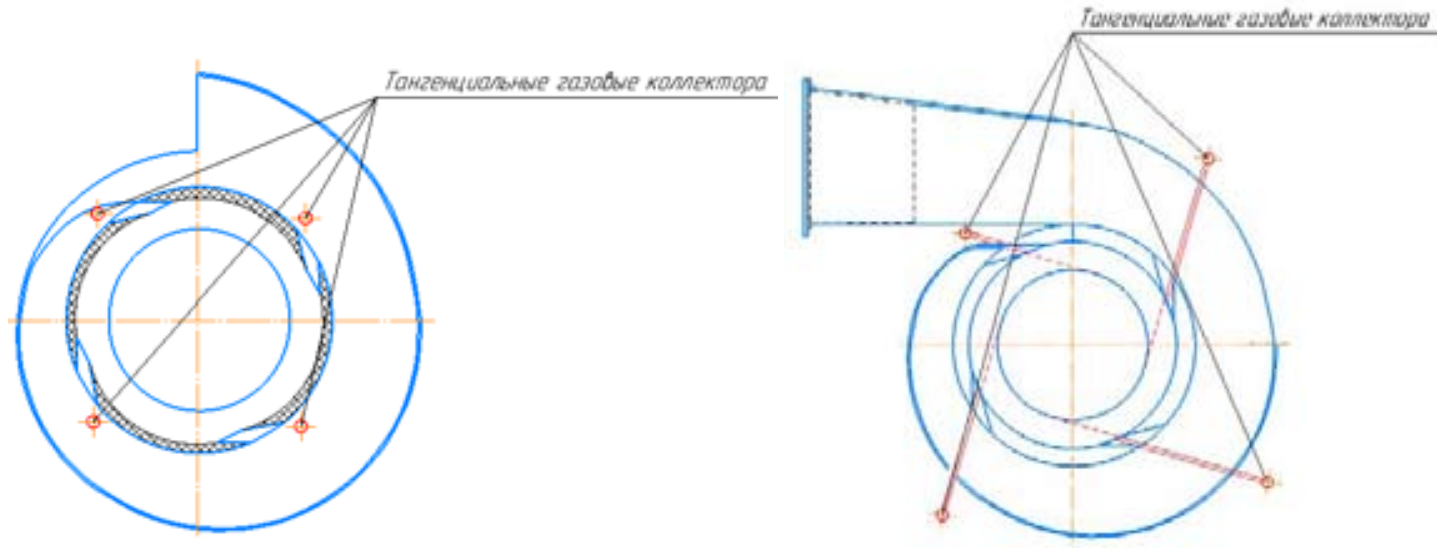

Рис. 4. Варианты конструкции тангенциальных газовых вводов

Fig. 4. Design options for tangential gas inlets

При определении оптимального распределения газа в камеру сгорания ЦВП котла БКЗ120-100МЦ были рассмотрены следующие варианты:

1. Центральный ввод газа. При этом вводе удалось достичь паропроизводительности 147 т/ч при избытке воздуха альфа 1,21, но выбросы оксидов азота, приведенные к $\alpha=1,4$, составили $170 \mathrm{Mг} / \mathrm{M}^{3}$.

2. Осевой и торцевой ввод газа. При нагрузке 137 т/ч и $\alpha=1,17$ выбросы оксидов азота, приведенные к $\alpha=1,4$, составили 140 мг $/ \mathrm{M}^{3}$, но при таком распределении наблюдалась сильная вибрация ЦВП.

3. Торцевой, осевой и односторонний тангенциальный подвод газа. При нагрузке 132 т/ч и $\alpha=1,13$ выбросы оксидов азота, приведенные к $\alpha=1,4$, составили 127 мг/м³ пределении факел ложился на стену топочной камеры, что могло вызвать пережог экранных поверхностей нагрева.

4. Четырехсторонний тангенциальный подвод газа с полным предварительным смешением позволил достигнуть нагрузки 149 т/ч при $\alpha=1,02$. При данной компоновке циклонный предтопок эксплуатировался на номинальной нагрузке с тангенциальным соотношением $\alpha=1$,

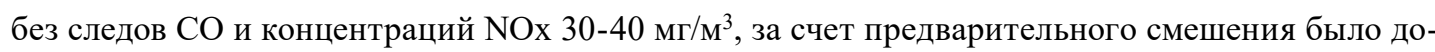
стигнуто практически полное сгорание в камере ЦП (метод сжигания с низкими избытками воздуха). Несмотря на высокие экономические и экологические показатели, тепловые напряжения камеры сгорания были настолько велики, что встал вопрос о надежности эксплуатации тангенциальных воздушных вводов.

\section{Проведение исследований внутри камеры сгорания}

Циклонный предтопок котла КВГМ-100-150МЦ Владивостокской ТЭЦ-1 был реконструирован с возможностью ввода измерительного зонда для измерений параметров внутри камер сгорания. Отверстия размещены на расстоянии 0,51 м за первым тангенциальным газовым вводом и 0,99 м в районе последнего газового ввода соответственно (рис. 5). Схема измерения позволяет проводить газовый анализ измерением основных компонентов продуктов сгорания 


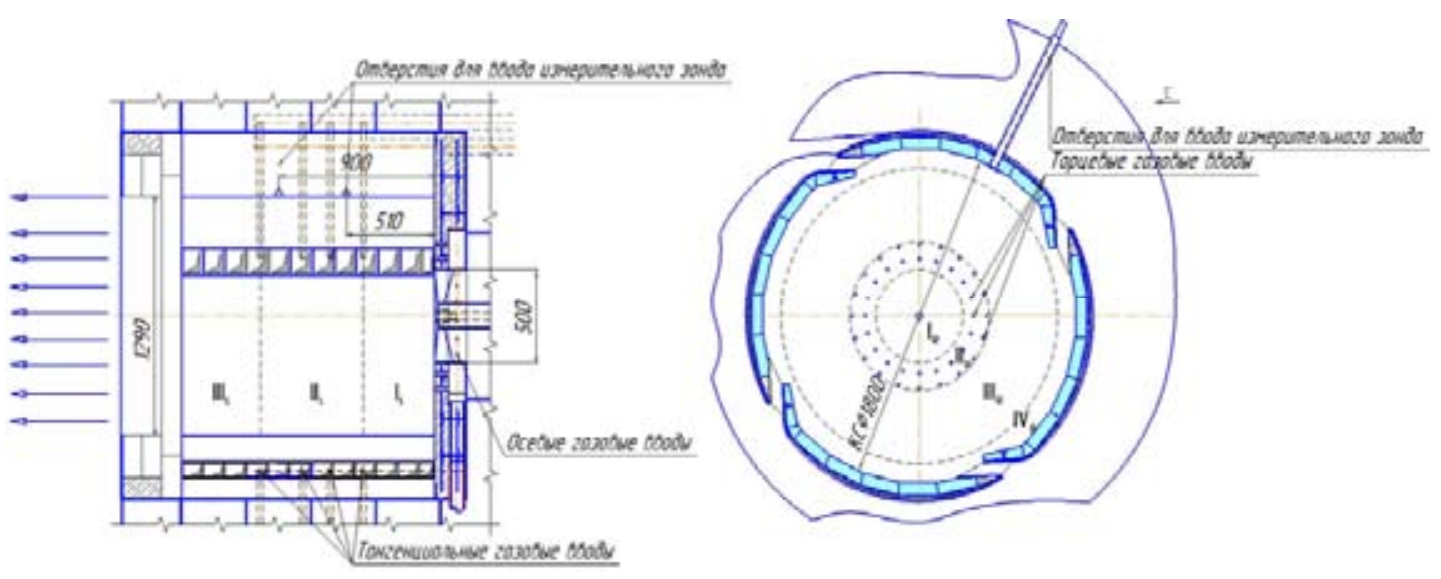

Рис. 5. Реконструированный предтопок мощностью 65 МВт

Fig. 5. Reconstructed pre-heating with a capacity of $65 \mathrm{MW}$

$\left(\mathrm{O}_{2}, \mathrm{CO}, \mathrm{CO}_{2}, \mathrm{NO}, \mathrm{NO}_{2}, \mathrm{CH}_{4}\right)$, температуры газов методом отсасывающего пирометра, а также статический и полный напоры и направление движения потока [2]. Подробное описание схемы измерений приведено в работе [3]. Для удобства разобьем камеру сгорания на зоны $\mathrm{I}_{\mathrm{L}}-\mathrm{III}_{\mathrm{L}}$ (от торца до пережима) по длине камеры сгорания и $\mathrm{I}_{\mathrm{R}}-\mathrm{IV}_{\mathrm{R}}$ (от оси до стенки) по ее радиусу соответственно (рис. 5).

Данное разбиение на зоны было приведено исходя из нижеследующего. По длине камеры сгорания: $\mathrm{I}_{\mathrm{L}}=0,41 \mathrm{~m}$ - зона развития факела, создаваемого торцевыми и осевыми вводами; $\mathrm{II}_{\mathrm{L}}=0,6 \mathrm{M}$ - зона формирования комбинированного факела за счет взаимодействия тангенциальных и торцевого вводов; $\mathrm{III}_{\mathrm{L}}=0,455 \mathrm{~m}-$ зона взаимодействия комбинированного факела и обратных токов из топки котла. По радиусу камеры сгорания применено следующее разбиение на зоны: $\mathrm{I}_{\mathrm{R}}=0,25 \mathrm{M}$ - зона окончательного формирования комбинированного факела; $\mathrm{II}_{\mathrm{R}}=0,15 \mathrm{~m}$ - зона начала формирования комбинированного факела (аэродинамически зоны $\mathrm{I}_{\mathrm{R}}$ и $\mathrm{II}_{\mathrm{R}}$ формируют ядро зоны квазитвердого вращения); $\mathrm{III}_{\mathrm{R}}=0,4 \mathrm{M}-$ зона развития факелов тангенциальных вводов; $\mathrm{IV}_{\mathrm{R}}$ - пристенная область.

Исследования процессов горения проводили в диапазоне нагрузок котла от 48 до 100 Гкал/ч с контролем параметров работы и выбросов загрязняющих веществ в уходящих газах, для чего привлекалась сертифицированная экологическая лаборатория. Ниже изложены результаты исследований, наиболее четко описывающие экологические показатели работы котлов с циклонными предтопками и методы снижения выбросов оксидов азота в них.

Все измерения осуществляли при положительных температурах наружного воздуха. На графиках приведены результаты измерения по радиусу камеры сгорания ЦВП от стенки камеры к оси соответственно (0 - ось камеры сгорания). При минимальной нагрузке котла 56 МВт наблюдается практически мгновенный рост температуры продуктов сгорания у стенки 430$450{ }^{\circ} \mathrm{C}$. Максимальные температуры $1420-1450{ }^{\circ} \mathrm{C}$ в последнем перед пережимом сечении наблюдаются на радиусе 0,45 м (конечная часть зоны $\mathrm{III}_{\mathrm{R}}$ ). Зона активного образования оксидов азота составляет 0,4 м и простирается на радиусах 0,5-0,15 м (зоны $\mathrm{I}_{\mathrm{R}}$ и $\mathrm{II}_{\mathrm{R}}$ ), при дальнейшем приближении к оси циклов наблюдается снижение концентраций за счет разбавления приосе- 
вым потоком продуктов сгорания. Максимальная концентрация фиксируется на радиусе 0,15 м и составляет 670-685 мг/м³ (рис. 6). При этом коэффициент избытка воздуха в уходящих газах

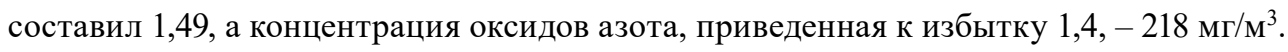

Уровень температур, а также относительно низкие скорости потока и их распределение по радиусу камеры сгорания свидетельствуют о том, что основная доля топлива порядка 80 \% при низких нагрузках сгорает именно в камере сгорания. Об этом также свидетельствует высокий уровень (для природного газа) оксидов азота в уходящих газах, характерный для устройств с высокими тепловыми напряжениями.

При высоких нагрузках 80-116 МВт картина кардинально меняется. Характеристики топочного процесса для камеры сгорания при нагрузке котла 105 МВт приведены на рис. 7. С ростом нагрузки происходит интенсификация процессов смесеобразования и удается значительно снизить избыток воздуха, подаваемого на горение. В отличие от низких нагрузок в пристенной зоне $\left(\mathrm{IV}_{\mathrm{R}}\right)$ наблюдаются гораздо более низкие температуры, 100-150 ${ }^{\circ} \mathrm{C}$. Зона активного горения в предтопке распространяется на радиусах 0,7-0 м (зоны $\mathrm{I}_{\mathrm{R}}-\mathrm{III}_{\mathrm{R}}$ ), уровень температур значительно падает, максимальные температуры не превышают $1200{ }^{\circ} \mathrm{C}$. Зона

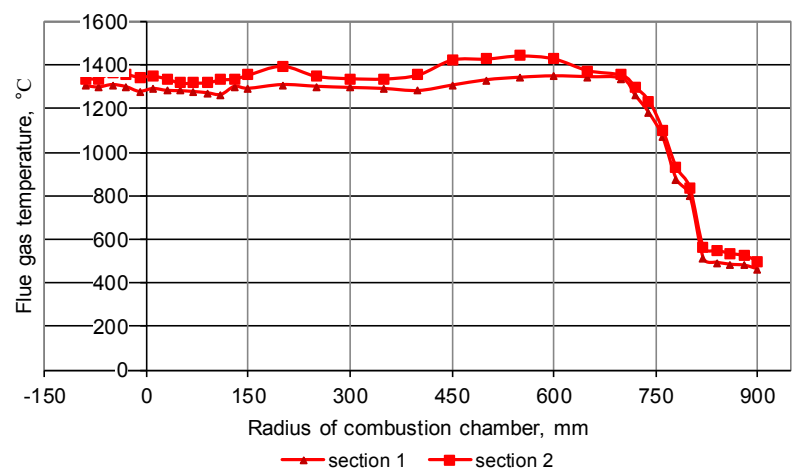

a)

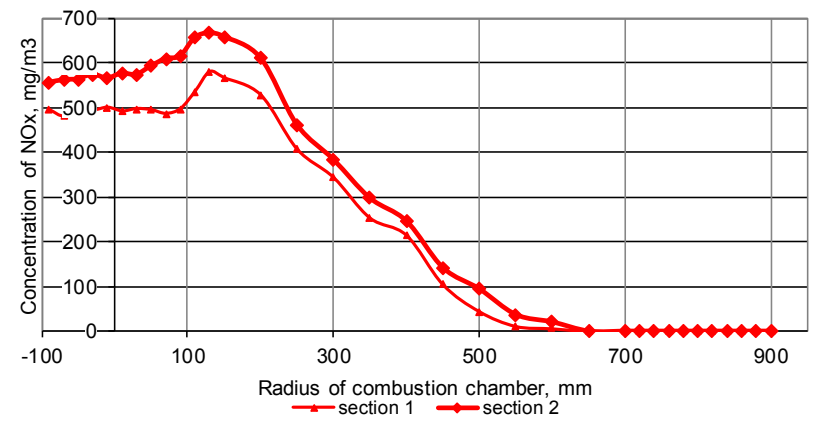

b)

Рис. 6. Параметры топочного процесса в камере сгорания при нагрузке котла 56 МВт: а - изменение температуры по радиусу камеры сгорания; $b$ - изменение концентрации оксидов азота по радиусу камеры сгорания

Fig. 6. Parameters of the combustion process in the combustion chamber at a boiler load of $56 \mathrm{MW}$ : a - temperature variation along the radius of the combustion chamber; $b$ - concentration of nitrogen oxides variation along the radius of the combustion chamber 


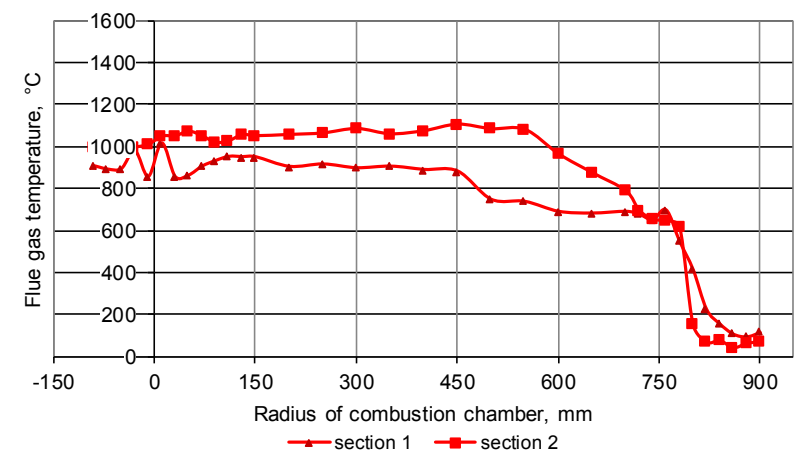

a)

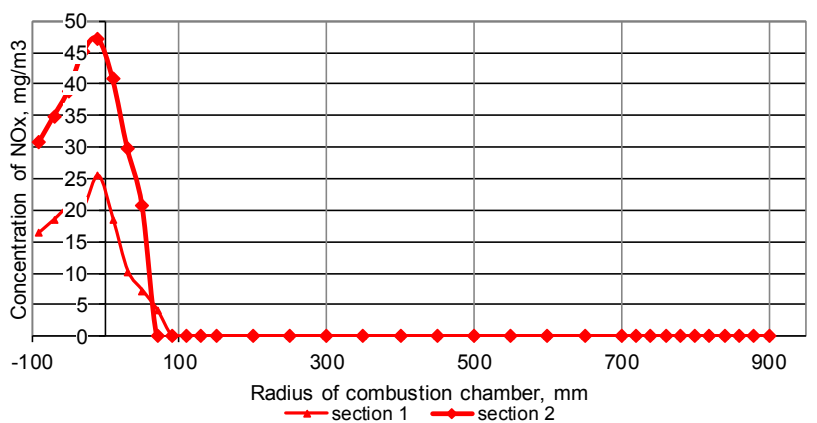

b)

Рис. 7. Параметры топочного процесса в камере сгорания при нагрузке котла 105 МВт: а - изменение температуры по радиусу камеры сгорания; $\mathrm{b}$ - изменение концентрации оксидов азота по радиусу камеры сгорания

Fig. 7. The parameters of the combustion process in the combustion chamber at a boiler load of $105 \mathrm{MW}$ : a temperature variation along the radius of the combustion chamber; $b$ - concentration of nitrogen oxides variation along the radius of the combustion chamber

очагов генераторов оксидов азота уменьшается до радиусов 0,1-0 м (зона $\mathrm{I}_{\mathrm{R}}$ ). Максимально измеренная концентрация оксидов азота в предтопке не превышает $50 \mathrm{Mг} / \mathrm{M}^{3}$, при этом значительная их часть вносится приосевыми потоками. Избыток воздуха в уходящих газах 1,117. Концентрация оксидов азота в уходящих газах, приведенная к избытку воздуха 1,4 , составляет 79 мг/м³ . По общему уровню температур в камере сгорания, концентрации оксидов азота в предтопке и уходящих газах можно сделать предположение о наличии второй зоны активного горения, расположенной в топке котла. При это доля топлива, сгорающая в предтопке на высоких нагрузках, равна 20-40 \%. Очевидно, что многолетние наблюдения авторов за котлами с ЦВП и их экологическими показателями подтверждаются. И с ростом нагрузки удельная концентрация оксидов азота в уходящих газах снижается со снижением доли топлива, сгорающей в первой зоне активного горения, и падением удельных тепловых напряжений камеры сгорания.

Одним из методов снижения выбросов NOx является ввод влаги в зону активного горения. На нагрузках 70-79 МВт на котле КВГМ-100-150МЦ производили впрыск воды в КС ЦВП с помощью разных центробежных механических форсунок с разным водотопливным соотноше-

$$
-77-
$$


нием, каждый опыт сопровождался измерениями внутри камеры сгорания и контроля параметров работы котла в уходящих газах.

На нагрузке 79 МВт был произведен впрыск с помощью 19-сопловой центробежной форсунки с водотопливным соотношением 0,15 (рис. 8). До впрыска при коэффициенте избытка

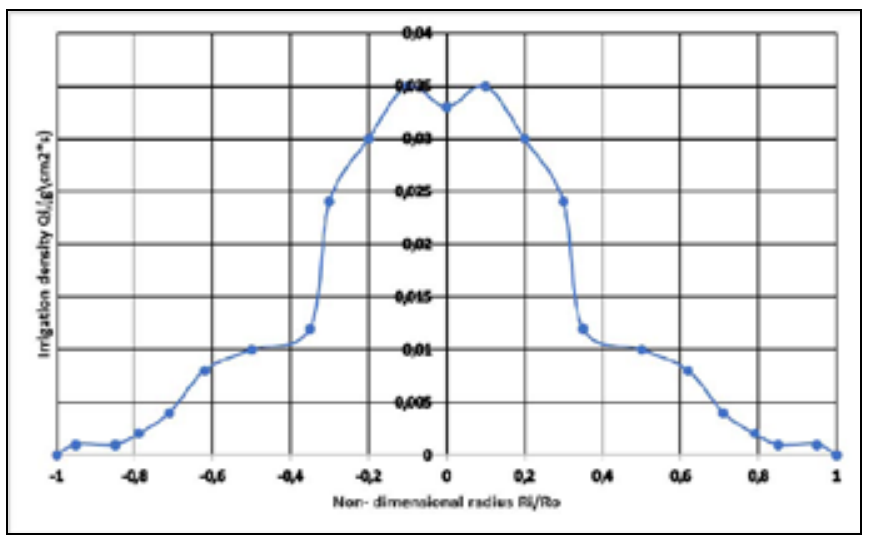

a)

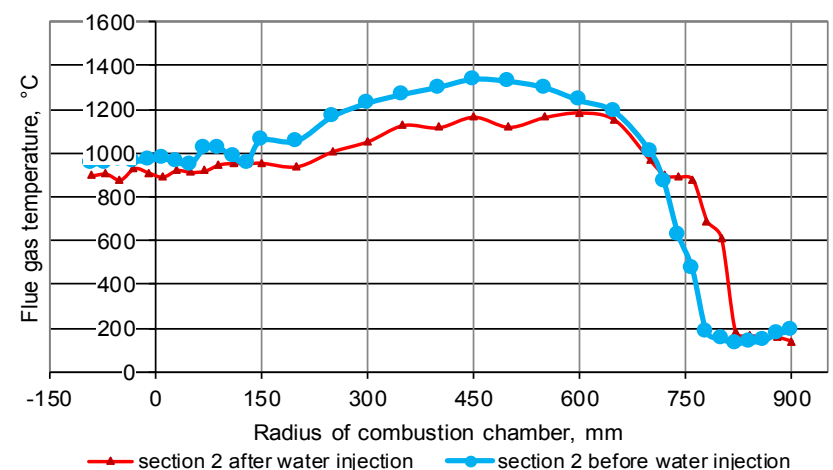

b)

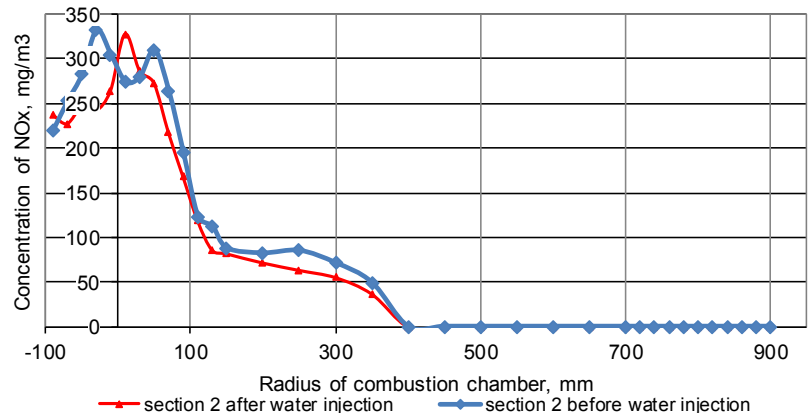

c)

Рис. 8. Плотность орошения и параметры топочного процесса до и после впрыска воды с помощью 19-сопловой форсунки: a - плотность орошения 19-сопловой форсунки; b - изменение температуры факела по радиусу камеры сгорания; с - изменение концентрации оксидов азота по радиусу камеры сгорания

Fig. 8. Irrigation density and combustion process parameters before and after water injection by means of a 19 nozzles atomizer: $\mathrm{a}$ - irrigation density of a 19 nozzles atomizer; $b$ - variation a flame temperature along the radius of the combustion chamber; $\mathrm{c}$ - concentration of nitrogen oxides variation along the radius of the combustion chamber 
воздуха 1,4 выбросы оксидов азота составили 175 мг/м³. После впрыска воды наблюдается рост температуры близ пристенной области на радиусах 0,8-0,75 м. Это связано с его замедлением за счет взаимодействия части тангенциального газового потока с распространяющимся потоком водяных паров и последующим более ранним сгоранием в этой области.

При плотности орошения, создаваемой данной форсункой, наблюдается лишь незначительное снижение температур в камере сгорания и смещение зоны очагов генераторов оксидов азота ближе к оси. Максимальная концентрация оксидов азота, зафиксированная в камере сгорания, снизилась с 350 до 335 мг/м². Незначительный впрыск воды не повлиял на техникоэкономические показатели работы котла, а снижение концентрации оксидов азота в уходящих газах составило 6 мг/м³ при коэффициенте избытка воздуха 1,4.

Максимального снижения выбросов NOx удалось достичь при работе котла на нагрузке 70 МВт и впрыске воды через односопловую центробежную механическую форсунку. Водотопливное соотношение составило 0,08 . Плотность орошения, создаваемая данной форсункой, такова, что водяной факел, создаваемый ею, попадает непосредственно в зоны с максимальной скоростью образования оксидов азота, расположенные на радиусах 0,45-0,3 м (зоны II $\mathrm{I}_{\mathrm{R}}-\mathrm{III}_{\mathrm{R}}$ ) от оси (рис. 9). До ввода воды в эту область максимальная концентрация оксидов азота достигала значений $332 \mathrm{Mг} / \mathrm{M}^{3}$, а температура была $1210-1250{ }^{\circ} \mathrm{C}$. После впрыска, соответственно, в зонах, подверженных непосредственному контакту с водой и отводу от них теплоты на ее испарение, температуры были снижены до 980-1020 ${ }^{\circ} \mathrm{C}$, а максимально измеренная концентрация составила $101 \mathrm{мг} / \mathrm{M}^{3}$. При текущем водотопливном соотношении влияние на технико-экономические показатели работы котла не выявлено. При коэффициенте избытка воздуха в уходящих газах 1,35 концентрация оксидов азота снижена с 189 до $132 \mathrm{мг} / \mathrm{M}^{3}$.

Опыты по впрыску воды показывают возможность снижения выбросов оксидов азота через штатный разъем для форсунки на низких нагрузках. Эффективность снижения NOx в зависимости от нагрузки и водотопливного соотношения составляет 25-35 \%.

За счет интенсивного смесеобразования на нагрузке 95 Гкал/ч удалось осуществить снижение выбросов оксидов азота с помощью контролируемого химического недожога $[4,5]$. Коэффициент избытка воздуха в уходящих газах изменялся в диапазоне 1,35-1,01 (рис. 10). Температура уходящих газов со снижением $\alpha$ также снижается со 125 до $117^{\circ} \mathrm{C}$.

\section{Определение влияния режимных факторов}

\section{на эмиссионные показатели}

Потеря теплоты с уходящими газами снижается с 6,5 до 4,8 \%. Концентрация СО в уходя-

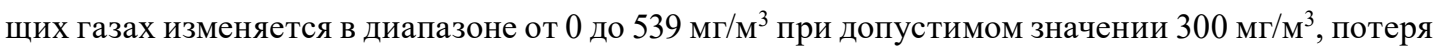
теплоты с химическим недожогом увеличивается с 0 до 0,197 \%. КПД котла увеличивается с 92,15 до $93,77 \%$.

Концентрация оксидов азота увеличивается от 45 мг $/ \mathrm{M}^{3}$ при коэффициенте избытка воздуха 1,1 до $121 \mathrm{мг} / \mathrm{M}^{3}$ при коэффициенте избытка воздуха 1,2 , это связано с увеличением свободного кислорода в первой и второй зонах активного горения. Далее следует снижение выбросов оксидов азота, и при коэффициенте избытка воздуха 1,34 концентрация составляет $90 \mathrm{Mг} / \mathrm{M}^{3}$. Снижение объясняется увеличением объемов воздуха, затрат теплоты на его прогрев и быстрое покидание первой зоны активного горения в камере сгорания. Для нагрузки 95 Гкал 


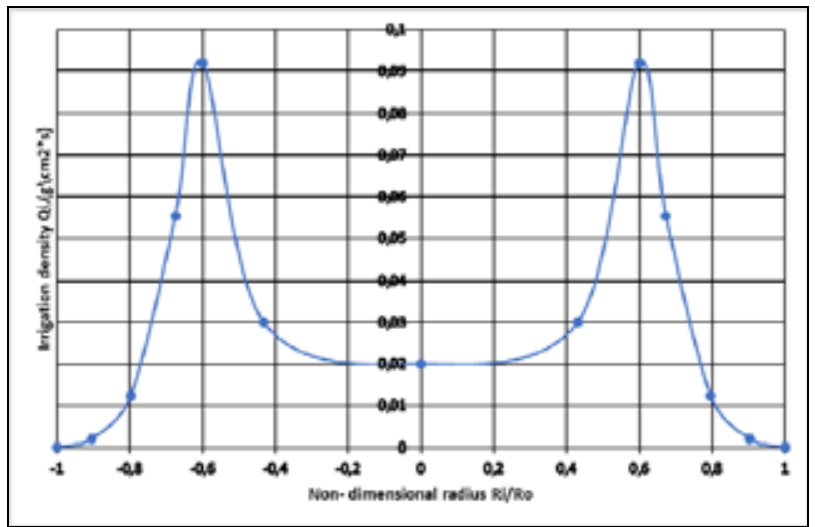

a)

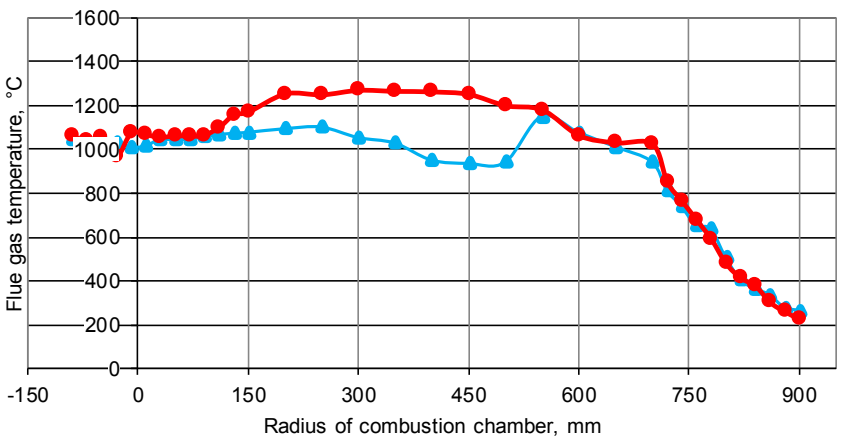

- section 2 after water injection

b)

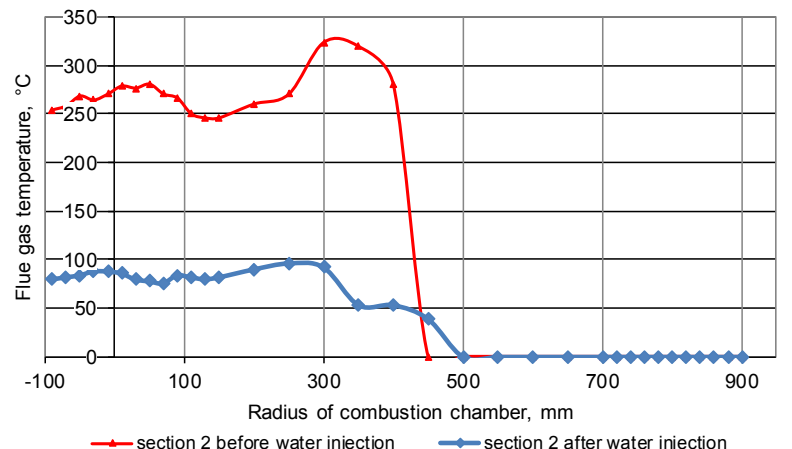

c)

Рис. 9. Плотность орошения и параметры топочного процесса до и после впрыска воды с помощью односопловой форсунки: $\mathrm{a}$ - плотность орошения односопловой форсунки; $\mathrm{b}$ - изменение температур по радиусу камеры сгорания; с - изменение концентрации оксидов азота по радиусу камеры сгорания

Fig. 9. Irrigation density and combustion process parameters before and after water injection using a single nozzle atomizer: $a$ - irrigation density of a single nozzle atomizer; $b$ - variation a flame temperature along the radius of the combustion chamber; $\mathrm{c}$ - concentration of nitrogen oxides variation along the radius of the combustion chamber

коэффициент избытка воздуха 1,06, при этом концентрация СО в уходящих газах составляет

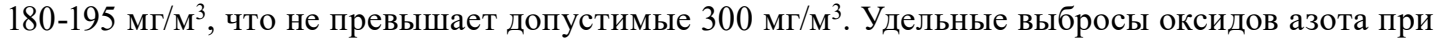

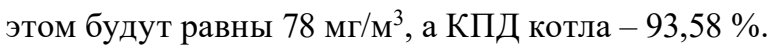




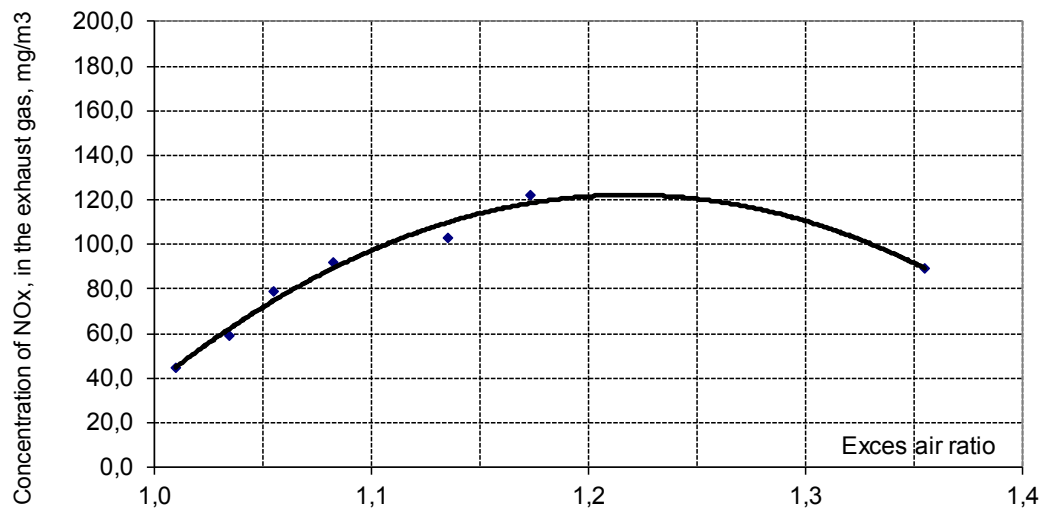

Рис. 10. Влияние коэффициента избытка воздуха в уходящих газах на выбросы оксидов азота

Fig. 10. The influence of the coefficient of excess air ratio in the exhaust gases on the nitrogen oxides emissions

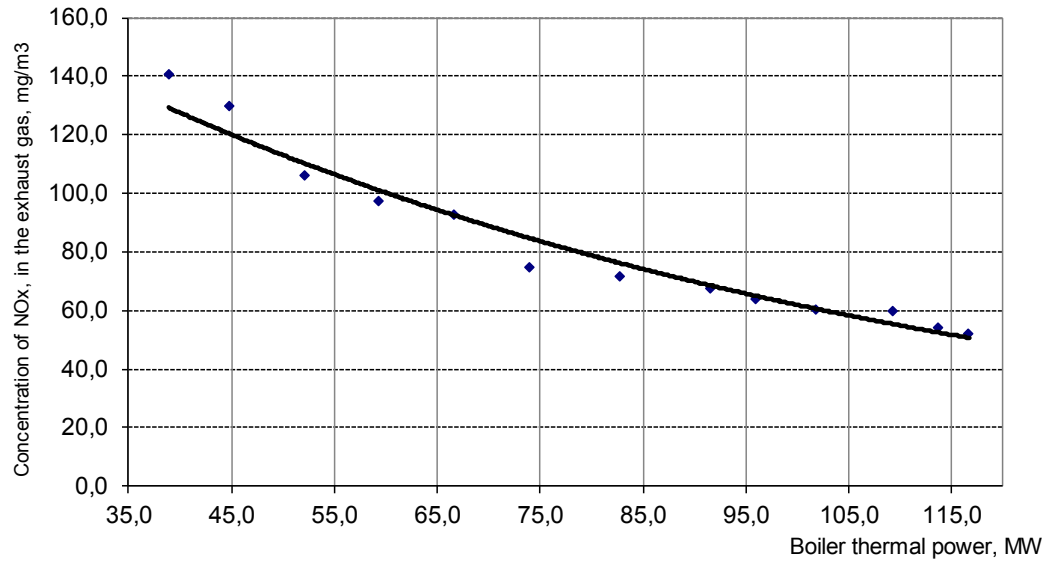

Рис. 11. Зависимость концентрации оксидов азота в уходящих газах при $\alpha=1,4$ от нагрузки котла КВГМ100-150МЦ

Fig. 11. The dependence of nitrogen oxides concentration in the exhaust gases at $\alpha=1.4$ on the load of the boiler KVGM-100-150MC

В процессе испытаний, проводимых на котле КВГМ-100-150МЦ ст№ 5, была составлена режимная карта малоэмиссионных режимов работы котла. Зависимость концентрации оксидов азота от нагрузки котла приведена на рис. 11. При нагрузках 38-75 МВт был осуществлен впрыск воды в камеру сгорания. Во всем вышеприведенном диапазоне работы котла водотопливное

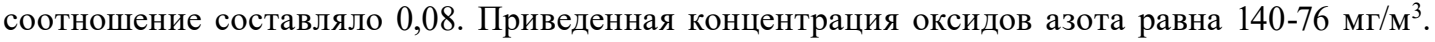
Помимо впрыска воды в данном диапазоне работы котла проводили сжигание с малыми избытками воздуха. На нагрузках 80-116 МВт котел эксплуатировали на перевернутой циркуляции котла (физический противоток), рассмотренной в [6]. В данном диапазоне нагрузок впрыск воды был прекращен, а в качестве мероприятия для более глубокого снижения выбросов $N O_{x}$ использовали контролируемый химический недожог. Концентрация оксидов азота снижается с ростом нагрузки с 75 до 47 мг/м³ превышает $300 \mathrm{Mr} / \mathrm{M}^{3}$. Следует также отметить, что примененные мероприятия позволяют со- 
хранить КПД котла в диапазоне 92,6-94,3 \%, наибольший КПД наблюдается при работе котла с реверсом циркуляции.

Для соответствия экологическим требованиям к котельным установкам в соответствии с ГОСТ Р 55173-2012 «Установки котельные. Общие технические требования» при эксплуатации котлов КВГМ-100-150МЦ на нагрузках 45-70 Гкал/ч рекомендуется вводить воду в первую зону активного горения, расположенную в камере сгорания. На нагрузках свыше 70 Гкал/ч появляется возможность применения контролируемого химического недожога, что позволит не только достичь выбросов оксидов азота ниже нормативных в 125 мг $/ \mathrm{M}^{3}$, но и повысить КПД котла на $0,5-1,2 \%$.

\section{Заключение}

В результате проделанной работы по снижению выбросов оксидов азота в котлах с воздухоохлаждаемыми циклонно-вихревыми предтопками можно сделать следующие выводы:

1. Предлагаемая технология по сжиганию природного газа в камерах сгорания с воздушным охлаждения обладает всеми признаками многостадийности, что делает ее конкурентоспособной с горелочной технологией.

2. Комбинированный ввод воздуха в ограниченное пространство камеры сгорания дает возможность повысить эффективность смесеобразования и максимально снизить коэффициент избытка воздуха, подаваемого на горение, что на высоких нагрузках позволяет дополнительно получить экологический эффект по снижению выбросов оксидов азота.

3. Комбинированный ввод топлива с возможностью перераспределения во время работы позволяет получить дополнительный эффект по снижению выбросов оксидов азота.

4. На основании проделанной работы подтверждается снижение выбросов оксидов азота с ростом нагрузки на рассматриваемых котлах.

5. На низких нагрузках предлагаемая конструкция циклонно-вихревого предтопка позволяет производить впрыск воды с использованием штатных форсунок.

6. На котлах с воздухоохлаждаемыми камерами сгорания возможно применение классических методов снижения выбросов оксидов азота, таких как ввод влаги в зону активного горения, сжигание с низкими избытками воздуха, контролируемый химический недожог. При этом воздействие осуществляется непосредственно на зону активного горения, ограниченную объемом камеры сгорания. Экологический эффект от примененных мероприятий дает возможность снижения выбросов оксидов азота на 30-80 \% без изменения конструкции котла или циклонно-вихревого предтопка.

\section{Список литературы / References}

[1] Штым А.Н., Штым К.А., Дорогов Е.Ю. Котельные установки с ииклонными предтопками, Владивосток: Изд. дом ДВФУ, 2012. 353 с. [Shtum A.N., Shtum K.A., Dorogov E.Yu. Boilers with cyclone-vortex pre-furnaces, Vladivostok, FEFU Publishing house, 2012, 353 p. (in Russian)]

[2] Лесных А.В., Штым К.А., Соловьева Т.А. Методы снижения эмиссии оксидов азота NOx при циклонно-вихревом сжигании топлив. Сборник трудов международной научной конференции молодых ученных и специилистов «Экология энергетики 2017». М.: МЭИ, 2017, 24-27 [Lesnykh A.V., Shtum K.A., Solovyova T.A. Nitrogen oxides emissions reduction methods during 
cyclone vortex combustion of fuels, Works of the international scientific conference of young scientists and specialists «Energy ecology - 2017» Moscow: MPEI, 2017, 24-27 (in Russian)]

[3] Соловьева Т.А. Совершенствование прочесса сжигания природного газа в котельных установках с ииклонными предтопками, автореф. дис. ... канд. техн. наук. Красноярск, 2017, 20 c. [Solovyova T.A. Improving the process of natural gas combustion in boilers with cyclone prefurnaces, Thesis ... cand. of tech. Sci. Krasnoyarsk, 2017, 20 p. (In Russian)]

[4] Росляков П.В. Современные воздухоохранные технологии на тепловых электростанциях (обзор). Теплоэнергетика, 2016, 7, 46-62 [Roslyakov P.V. Modern air protection technologies in thermal power plants (overview), Thermal Engineering., 2016, 7, 42-62 (in Russian)]

[5] Росляков П.В., Плешанов К.А., Ионкин И.Л. Оптимальные условия для сжигания топлива с контролируемым химическим недожогом. Теплоэнергетика, 2010, 4, 17-22 [Roslyakov P.V., Pleshanov K.A., Ionkin I.L. The optimal conditions for firing fuel with controlled incomplete combustion, Thermal Engineering, 2010, 4, 17-22 (in Russian)]

[6] Штым К.А., Соловьева Т.А. Модернизация котлов КВГМ-100-150 на циклонно-вихревое сжигание газа. Теплоэнергетика, 2015, 3, 48 [Shtum K.A., Solovyova T.A. Conversion of KVGM100-150 boilers to cyclone-swirl burning of gas, Thermal Engineering, 2015, 3, 48 (in Russian)] 